Stereotactic
and Functional
Neurosurgery

Stereotact Funct Neurosurg 2006;84:131-135

DOI: $\underline{10.1159 / 000094844}$

Published online: August 4, 2006

\title{
Evolution of Basal Ganglia Surgery for Movement Disorders
}

\author{
Philip L. Gildenberg \\ Department of Neurosurgery, Baylor Medical College, Houston, Tex., USA
}

\section{Key Words}

Functional neurosurgery • Basal ganglia • Ansotomy • Pallidotomy • Thalamotomy • Movement disorders • Parkinson's disease

\begin{abstract}
In 1942, it was thought that basal ganglia surgery would cause permanent unconsciousness and significant impairment of motor control. By 1947, when human stereotactic surgery was introduced, the first target was the globus pallidus in a patient with chorea. What happened during those 5 years to set the stage for stereotactic surgery? During the last half of the 19th century, it was first noted that motor disorders were often accompanied by atrophy of various parts of the basal ganglia, and when histopathology became part of necropsy, that relationship between movement disorders and the basal ganglia was strengthened. The impairment of fine motor control was noted in experiments that involved lesioning the basal ganglia, which led to the conclusion that disease of the basal ganglia might cause motor impairment. Finally, in 1939, Russel Meyers took the bold move of surgically resecting the head of the caudate nucleus at craniotomy in a patient with Parkinson's disease, demonstrating that Dandy was wrong in the view that the basal ganglia were the center of consciousness, and that symptoms and motor control might be improved by caudate lesions without motor
\end{abstract}

Presented at the Meeting of the World Society for Stereotactic and Functional Neurosurgery, Rome, June 15, 2005.

\section{KARGER \\ Fax +41613061234 E-Mail karger@karger.ch} www.karger.com

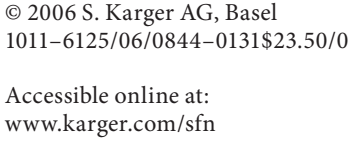

impairment. He reported his first patient in a meeting in 1940 , which was published in 1942, and was encouraged to investigate basal ganglia surgery further. Although results were encouraging, the mortality rate was prohibitive. Since the introduction of pallidoansotomy in 1947, basal ganglia surgery has become both safe and effective and has been expanded and refined.

Copyright $\odot 2006$ S. Karger AG, Basel

The basal ganglia were considered a surgical noli me tangere. This admonition originated with Dandy [1], who concluded, based on observation in two cases with surgical vascular injury, that the 'seat of consciousness' lay in the distribution of the left anterior cerebral artery just posterior to the splenium of the corpus callosum, which was considered to include the anterior portions of the basal ganglia.

A Meeting of the Association for Nervous and Mental Disease was held in New York in 1940, which included most of the authorities in the basal ganglia at that time, including Lewy, Bucy, Doshay, Dusser de Barenne, Fulton, Klemme, Lewy, Merritt, Mettler, Papez, Putnam, Ranson, and a little known neurosurgeon from New York, Russel Meyers [2]. The all-star participants provide a picture of the state of knowledge frozen in time. The proceedings of this excellent meeting were first published in 1942 (and reprinted in 1966) without correction or comment, so one may assume that the same ideas were still held in 1942. Since little new information was added between that meeting and the introduction of human ste-

Philip L. Gildenberg, MD, PhD

Clinical Professor of Neurosurgery, Baylor Medical College

Houston Stereotactic Concepts, Inc.

$2260 \mathrm{~W}$ Holcombe Blvd, Suite 309, Houston, TX 77030 (USA)

Tel. +1 713664 3592, Fax +1 713669 0388,E-Mail hsc@stereotactic.net 


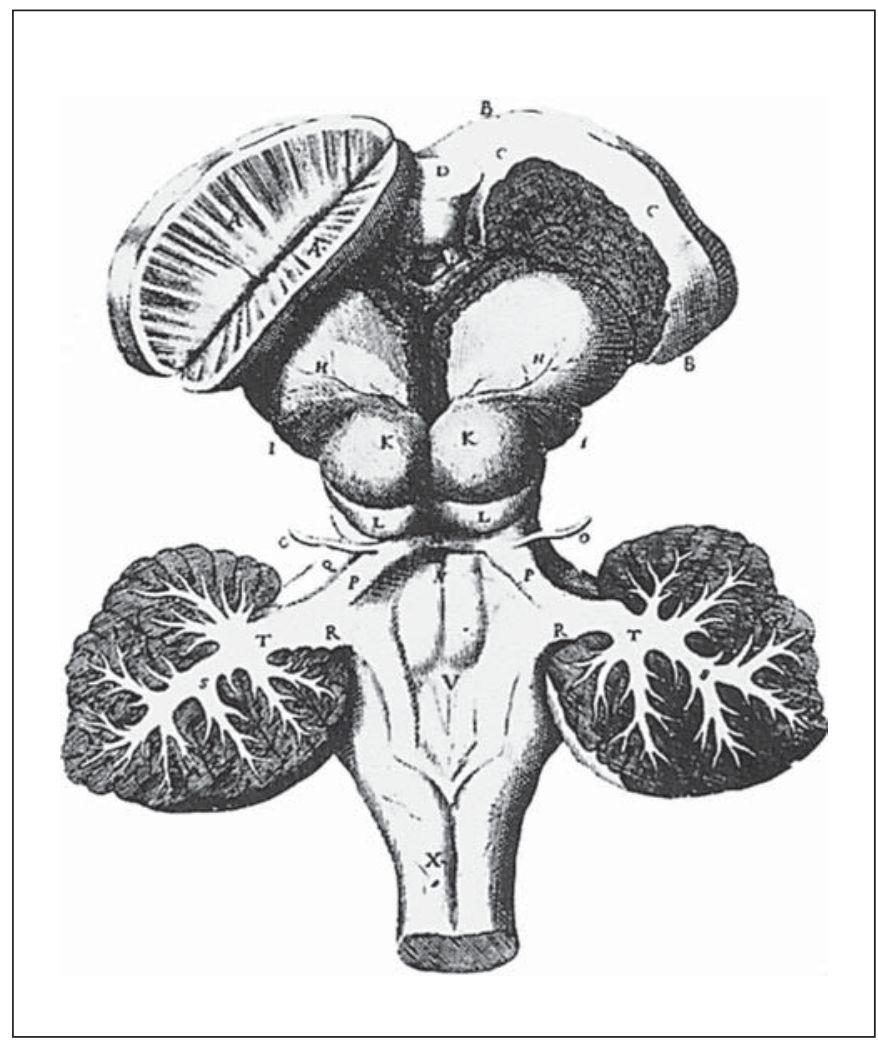

Fig. 1. Brain stem of a sheep, illustrated by Sir Christopher Wren in Thomas Willis' Anatome [cited in 3].

reotactic pallidotomy in 1947, we have some indication of what information led Spiegel and Wycis to select pallidotomy for treatment of Huntington's chorea as their fist human stereotactic procedure.

The anatomy of the components of the basal ganglia was reviewed by Lewy [3] at that meeting. He reviewed how the basal ganglia were first defined by Thomas Willis as early as 1664 in a book beautifully illustrated by Sir Christopher Wren (fig. 1), but their function, remained a mystery until the twentieth century. In 1664, Willis was confident enough to speculate that 'the corpus striatum represents an exchange between brainstem and cortex' [cited in 3]. However, little progress was made, and by 1911, Edinger had to confess, 'We lack any knowledge of the function of the corpus striatum or of the symptoms following its stimulation or destruction' [4].

Pathology of the basal ganglia was noted by Oppolzer in 1861 on necropsy that there were foci of abnormality in the basal ganglia in patients with Parkinson's disease [5]. Broadbent [6] noted basal ganglia atrophy in chorea in 1865, which was also reported by Gowers [7] in 1876 in

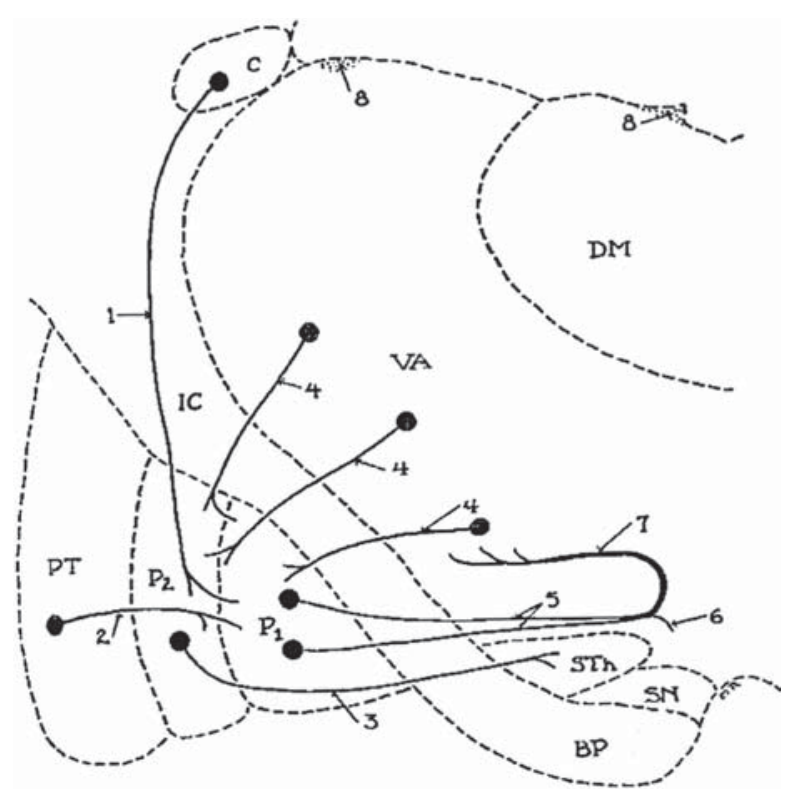

Pig. 26. 1)iagrammatic representation of sone of the fiber ennnections of the corpus triattum. (: enudate nuc'cus; DM, nucleus medialis dorsalis; $\mathrm{LC}$; intectal eapsule; $P_{6}$, internal division of globus pallidus; $l_{3}$, external division of glohus pallidus; $P^{2} T$, putamen; SV, substantis nigra; STh, subthlakutuic uucieus; VA, nucleus ventralix anterior; 1 and 2, striopallidal filerx; 3, pailidosnbthalanic fiber; 4, thulamopillidal fbers: 3, fassiculus lentienlntix; 6, pallidohypothnlamic fiber; 7 , faviculus thalnmicus; \&. pallidohalienular tract.

Fig. 2. Diagram of basal ganglia pathways by Ranson and Ranson, 1942 [46].

patients with athetosis. Three years later, Ringer [8] declared that 'athetosis is due to atrophy and degeneration of the basal ganglia'. These observations were particularly insightful, since it was not until the first decade of the 20th century that histological staining was introduced into necropsy, and the involvement of the basal ganglia in movement disorders was verified. Lewy [9] documented the histological characteristics of Parkinson's disease in 1912.

Information about the physiology of the basal ganglia began to emerge during the first half of the 20th century. In 1921, on the basis of animal experimentation and clinical observation, Foerster [10] stated that the corpus striatum is a center for the integration of elemental movement patterns into hierarchies of automatic associated acts. In 1937, Magoun et al. [11] speculated that emotional expression, at least in part, is subtended by the basal ganglia (fig. 2).

In 1909, Horsley [12] performed the first surgery to treat a movement disorder, when he ablated the precentral cortex in a patient with hemiathetosis. He was able to abolish 
the abnormal movement, but at the price of hemiplegia, with all its attendant abnormalities. He drew the conclusion that it was necessary to interrupt the primary motor system in order to alleviate involuntary movements, a view that was held through 1942 and beyond [13].

In an attempt to avoid such motor complications, attention was directed to the spinal cord, with operations that were least likely to cause paralysis. Foerster performed posterior rhizotomy in 1913 [14, 15] for dyskinesia. Other attempts involved operations such as sympathectomy by Royle [16] in 1924, and dorsal column section by Puusepp in 1930 [15].

Since those operations had only slight, if any, success, attention was drawn back to cortical ablation. In 1932, Bucy and Buchanan [17] reported ablation of Brodmann areas 4 and 6 , and later added areas 8,9 , and 10, to treat athetosis and Parkinson's disease, and reported that improvement was commensurate to the amount of weakness or paralysis resulting from surgery [18] (fig. 3). By 1939 , Bucy and Case $[13,18]$ concluded that the pyramidal tract had to be at least partially included for any procedure to be successful, a view Bucy maintained through the 1980s [13]. However, in about 1940, Klemme [19] was able to obtain some relief by sparing area 4 and confining the cortical ablation to the premotor area 6 , but not without undesirable symptoms of hemiparesis.

In an attempt to obtain improvement in involuntary movements without hemiplegia, in 1935 Delmas-Marsalet and Von Bogaert [20] extirpated the dentate nucleus with some success, but with significant risk.

At the 1940 meeting, Bucy [13] summarized his results after ablation of motor cortex, which represented the dominant surgical opinion, acknowledging that all patients relieved of Parkinson symptoms suffered hemiplegia, spasticity dyspraxia, hyperreflexia, clonus, and spreading reflexive synergies with an operative mortality rate of $10 \%$. Klemme [19] reported his cortical extirpation limited to only area 6 in 100 patients operated between 1937 and 1940 with unilateral dystonia symptoms and noted reasonably good results with fewer neurological sequelae, but with $17 \%$ mortality.

The state of physiological knowledge was also summarized at that 1940 meeting. Kennard and Fulton [21] observed that bilateral pallidal lesions in the cat and monkey caused tremor, whereas after unilateral ablation 'all movements were greatly slowed'. It was the observation of such slowing (plus the relationship of pallidal atrophy with bradykinesia after $\mathrm{CO}$ poisoning) that later discouraged Spiegel and Wycis [22] from using pallidotomy in Parkinson's disease, for fear of increasing bradykinesia,

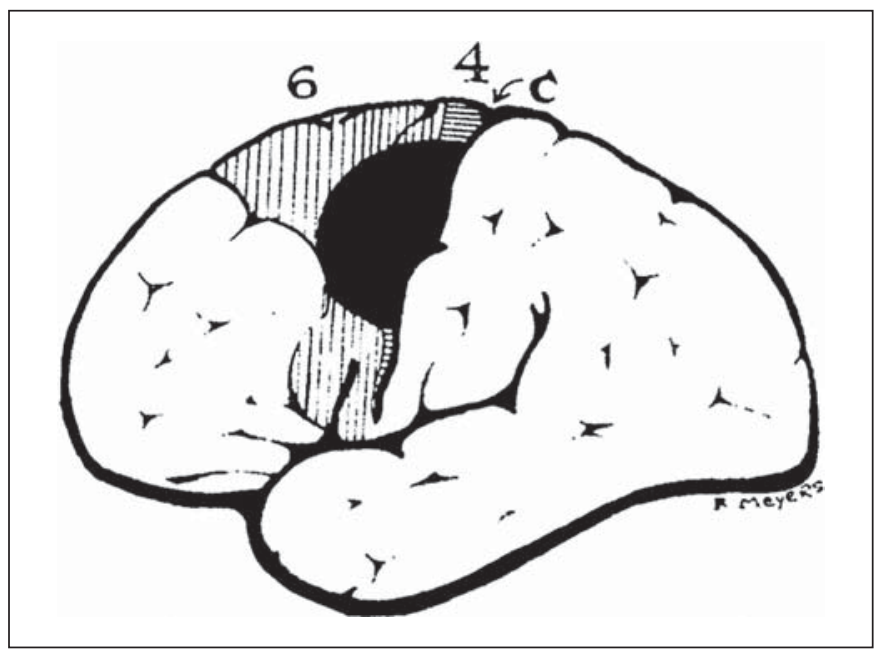

Fig. 3. Bucy's diagram of cortical ablation for movement disorders, 1942 [13].

although it was used for Parkinson's disease within the following few years by Hassler and Riechert [23], who preferred the target of the pallidofugal fibers in the ventrolateral thalamus, and soon after by others.

At that meeting, Lewy [3] noted that 'after one hundred years of laborious preliminary studies the "Gestalt" of the basal ganglia, their function and diseases, became suddenly visible around the year 1912', but there was still much disagreement about the physiological organization. Mettler [24] attempted to simplify concepts held at that time, when he opined that 'the pyramidal and extrapyramidal systems constitute a closely organized and interrelated functional unit ... The striatum occupies the position of an inhibitory mechanism ... The pallidum, as contrasted with the striatum, is a positive motor mechanism ....

At that meeting, all reports of surgical treatment of movement disorders involved the pyramidal system save one. Meyers [25] reported that in 1939 he had operated on a patient with Parkinson's disease by extirpating the head of the caudate nucleus via a transventricular approach at craniotomy (fig. 4). Not only did the patient not suffer unconsciousness (Dandy was wrong), but had significant improvement in symptoms of Parkinsonism without hemiplegia (Bucy was wrong). Following that meeting (possibly because of the encouragement he received from Tracy Putnam, the meeting organizer, in the meeting summarization), Meyers performed several variations of that operation, and by 1949 , reported 58 various basal ganglia procedures for that disease [26]. The most successful involved sectioning the ansa lenticularis 


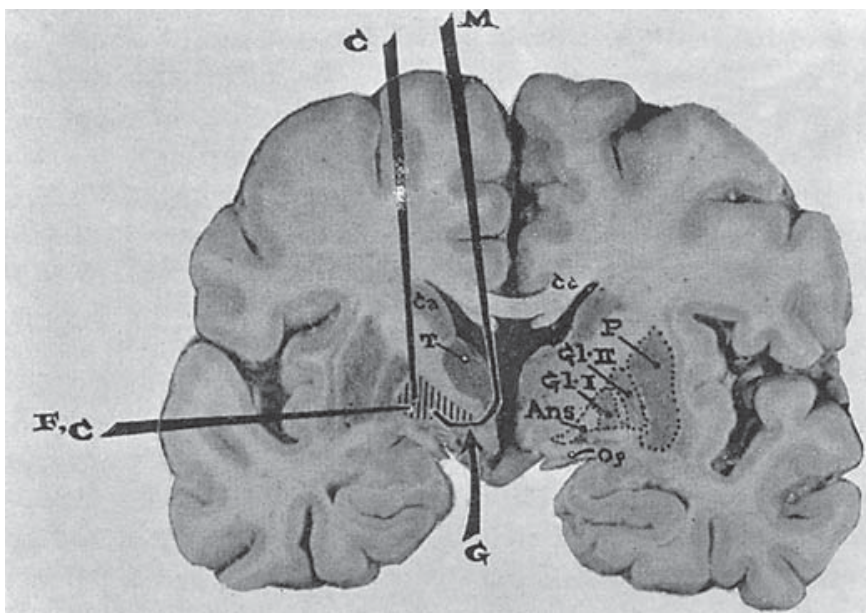

Fig. 4. Meyers' surgical approaches to the basal ganglia [26].

as it emerged from the pallidum. Sixty-two percent of patients had improvement, but the operative mortality rate was $12 \%$. The morbidity and mortality were sufficient so that Meyers himself advocated against such surgery.

The results of Meyers' surgery prior to 1947 were known to Spiegel and Wycis, and undoubtedly influenced their choice of pallidoansotomy as their first stereotactic procedure. Even though their results were more consistent and their mortality rate from the start was less than $1 \%$ [27], it took a decade for stereotactic surgery to become the commonly accepted standard practice. In the meantime, other nonstereotactic procedures for electrocoagulation of the ansa lenticularis for Parkinson's disease were introduced by Fenelon [28] in 1950 and modified in 1955 [29], and by Guiot and Brion [30] in 1952.

Meanwhile, attention was moving from the pallidum to the ventrolateral thalamus. In 1951, Hassler and Riechert [23] proposed a lesion in the ventrolateral thalamus, near the distal site of the pallidofugal fibers. The original lesion was large, and encompassed what were later defined as Voa, Vop, and Vim. Hassler's surgical associate Riechert performed thalamotomy at first for dyskinesia and then for Parkinson's disease, which was successful for both tremor and rigidity. In the meantime, Hassler [31] was evolving his subclassification of the thalamus. Autopsy studies on several patients who died of other causes some time after successful surgery suggested that Voa lesions relieved rigidity and Vop lesions (later moved to Vim) relieved tremor best [23]. Later, Bertrand, Jasper et al. [32], as well as Fukamachi, Ohye and Narabayashi [33] localized the target for tremor more discreetly to the Vim nucleus by using microelectrode recording.
During the first 5 years of stereotactic surgery, many targets that lay within the basal ganglia or connected to the basal ganglia were empirically tried for the treatment of various motor disorders. As early as 1952, Spiegel, Wycis et al. [34] summarized collective experience with lesions in the pallidum and thalamus, as well as lesions at the midbrain level, that were mainly for pain management. Lesions were made in the zona inserta and further distal in the pallidofugal pathways in Forel's field in the early 1960's [35], and in the subthalamic region throughout that decade by Mundinger and Ostertag [36], Story et al. [37] and Fager [38]. There was enough concern that the hemiballismus, which had been demonstrated in monkeys by Carpenter and Mettler [39] in 1949, might occur in patients, so the subthalamic nucleus did not become a popular target. The reports at that time were not always clear about whether the target lay in the subthalamic nucleus or in the subthalamic area.

During the 1960s, when there was a great deal of functional stereotactic surgery being done, the targets generally evolved to be Vim for tremor, pallidum, Voa or Vop thalamus, or Forel's field for Parkinson rigidity or bradykinesia, and the ventrolateral thalamus or pallidum for dyskinesia [40].

When L-dopa appear on the scene in 1968, however, most of the stereotactic activity ground to a halt [41]. It was not until Laitinen et al. [42] resurrected pallidotomy in 1992 that functional stereotactic surgery began to recover.

In the meantime, implantable stimulators for deep brain stimulation had appeared, so it was not long until lesions began to be replaced by stimulation. Both Siegfried [43, 44] and Benabid et al. [45] had reported improvement in motor control in patients who had had stimulators implanted for pain. In 1980, Brice and McClellan implanted stimulators in 2 patients with tremoraccompanying multiple sclerosis. In 1987, Benabid et al. [45] documented the benefit of stimulation of Vim for tremor and in stimulation of the subthalamic nucleus for other manifestations of Parkinsonism and related medication, including dyskinesia, while Lozano demonstrated the benefit of pallidal stimulation.

To return to our original question, 'What happened between 1942 and 1947 to set the stage for stereotactic surgical treatment of movement disorders?' (1) Knowledge about the anatomy and physiology of the basal ganglia was advanced, (2) Meyers proved that basal ganglia surgery could be done without impairing consciousness, and (3) Meyers also proved that extrapyramidal disease could be treated with basal ganglia surgery. 


\section{References}

1 Dandy WE: The Brain. Hagerstown, WF Prior Company, 1966.

2 Putnam TJ (ed): The Diseases of the Basal Ganglia. New York, Hafner Publishing, 1966.

3 Lewy FH: Historical introduction: the basal ganglia and their diseases; in Putnam TJ (ed): The Diseases of the Basal Ganglia. New York, Hafner Publishing, 1966, pp 1-20.

4 Edinger L: Vorlesungen über den Bau der nervösen Zentralorgane des Menschen und der Tiere. Leipzig, Vogel, 1911.

5 Oppolzer $\mathrm{H}$ : Fall von Paralysis agitans. Wien Med Wochenschr 1861;249-265.

6 Broadbent WH: Remarks on the pathology of chorea. Report before the London Med. Soc., 1865-1866. BMJ 1869;345-369.

7 Gowers WR: On athetosis and posthemiplegic disorders of movement. Med Chir Trans 1876;59:271.

8 Ringer S: Notes of a postmortem examination on a case of athetosis. Practitioner 1879; 23:161.

9 Lewy FH: Die pathologische Anatomie der Paralysis agitans. Lewandowskys Handb 1912;3:920.

-10 Foerster O: Zur Analyse und Pathophysiologie der striären Bewegungsstörungen. Z Ges Neurol Psychiatr 1921;73:1.

$\checkmark 11$ Magoun HW, Atlas D, Ingersoll EH, Ranson SW: Associated facial, vocal and respiratory components of emotional expression: an experimental study. J Neurol Psychopathol 1937; 17:241.

12 Horsley V: The function of the so-called motor area of the brain. BMJ 1909;2:125-132.

13 Bucy PC: Cortical extirpation in the treatment of involuntary movements; in Putnam TJ (ed): The Diseases of the Basal Ganglia. New York, Hafner Publishing, 1966, pp 551595.

14 Foerster O: On the indications and results of the excision of posterior spinal nerve roots in men. Surg Gynec Obstet 1913;16:463-475.

15 Puusepp L: Cordotomia posterior lateralis (fasc. Burdachi) on account of trembling and hypertonia of the muscles of the hand. Folia Neuropath Estomiona 1930;10:62.

16 Royle ND: A new operative procedure in the treatment of spastic paralysis and its experimental basis. Med J Aust 1924;1:77-86.

17 Bucy PC, Buchanan DN: Athetosis. Brain 1932;55:479-492.

18 Bucy PC, Case TJ: Tremor. Physiologic mechanism and abolition by surgical means. Arch Neurol Psychiatry 1939;41:721-746.
19 Klemme RM: Surgical treatment of dystonia. With report of one hundred cases; in Putnam TJ (ed): The Diseases of the Basal Ganglia. New York, Hafner Publishing, 1966, pp 596-601.

20 Delmas-Marsalet P, Von Bogaert L: Sur un cas de myoclonies rhythmique continués par une intervention chirurgicale sur le tronc cérébral. Rev Neurol 1935;64:728.

21 Kennard MA, Fulton JF: Corticostriatal interrelations in monkey and chimpanzee; in Putnam TJ (ed): The Diseases of the Basal Ganglia. New York, Hafner Publishing, 1966, pp 228-245

22 Spiegel EA: Guided Brain Operations. Basel, Karger, 1982.

23 Hassler R, Riechert T: Indikationen und Lokalisationsmethode der gezielten Hirnoperationen. Nervenarzt 1954;25:441-447.

24 Mettler FA: Relation between pyramidal and extrapyramidal function; in Putnam TJ (ed): The Diseases of the Basal Ganglia. New York, Hafner Publishing, 1966, pp 150-227.

25 Meyers R: The modification of alternating tremors, rigidity and festination by surgery of the basal ganglia; in Putnam TJ (ed): The Diseases of the Basal Ganglia. New York, Hafner Publishing, 1966, pp 602-665.

26 Meyers R: The surgery of the hyperkinetic disorders; in Vinken PJ, Bruyn GW (eds) Diseases of the Basal Ganglia. New York, North-Holland Publishing, 1968, pp 844878.

27 Spiegel EA, Wycis HT: Stereoencephalotomy. I. New York, Grune \& Stratton, 1952.

28 Fenelon F: Essais de traitement ceurochirurgical du syndrome parkinsonien par intervention directe sur les voies extrapyramidales immédiatement sous striopallidales (anse lenticulaire): communication suivie de projection du film d'un opérés pris avant at après l'intervention. Rev Neurol (Paris) 1950;83:437-440.

29 Fenelon F: La neuro-chirurgie de l'anse lenticulaire dans les dyskinesies et la maladie de parkinson. Sem Hôp Paris 1955;31:18351837.

30 Guiot G, Brion S: Traitement neurochirurgical de syndrome choreoathetosique et parkinsoniens. Sem Hôp Paris 1952;49:20952099.

31 Hassler R: Architectonic organization of the thalamic nuclei; in Schaltenbrand G, Walker AE (eds): Stereotaxy of the Human Brain. Stuttgart, Thieme, 1982, pp 140-180.

-32 Bertrand G, Jasper H, Wong A, Mathews G: Microelectrode recording during stereotactic surgery. Clin Neurosurg 1969;16:328355.
33 Fukamachi A, Ohye C, Narabayashi H: Delineation of the thalamic nuclei with a microelectrode in stereotaxic surgery for parkinsonism and cerebral palsy. J Neurosurg 1973;39:214-225.

34 Spiegel EA, Wycis HT, Freed H: Stereoencephalotomy in thalamotomy and related procedures. J Am Med Assoc 1952;148:446451.

35 Spiegel EA, Wycis HT, Szekely EG, Soloff L, Adams J, Gildenberg P, Zanes C: Stimulation of Forel's field during stereotaxic operations in the human brain. Electroencephalogr Clin Neurophysiol 1964;16:537-548.

36 Mundinger F, Ostertag C: Multilocular lesions in the therapy of cerebral palsy. Acta Neurochir (Wien) 1977;24(suppl):11-14.

37 Story JL, French LA, Chou SN, Meier MJ: Experiences with subthalamic lesions in patients with movement disorders. Confin Neurol 1965;26:218-221.

38 Fager CA: Evaluation of thalamic and subthalamic surgical lesions in the alleviation of Parkinson's disease. J Neurosurg 1968;28: 145-149.

39 Carpenter MB, Mettler FA: Analysis of subthalamic hyperkinesia in the monkey with special reference to ablations of the agranular cortex. J Comp Neurol 1951;95:125-157.

40 Gildenberg PL: History of movement disorder surgery; in Lozano A (ed): Movement Disorder Surgery. Progress and Challenges. Basel, Karger, 2000, pp 1-20.

41 Gildenberg PL: Whatever happened to stereotactic surgery? Neurosurgery 1987;20: 983-987.

42 Laitinen LV, Bergenheim AT, Hariz MI: Ventroposterolateral pallidotomy can abolish all parkinsonian symptoms. Stereotact Funct Neurosurg 1992;58:14-21.

43 Siegfried J: Sensory thalamic neurostimulation for chronic pain. Pacing Clin Electrophysiol 1987;10:209-212.

44 Siegfried J: Effect of stimulation of the sensory nucleus of the thalamus on dyskinesia and spasticity. Rev Neurol (Paris) 1986;142: 380-383.

45 Benabid AL, Pollak P, Louveau A, Henry S, de Rougemont J: Combined (thalamotomy and stimulation) stereotactic surgery of the VIM thalamic nucleus for bilateral Parkinson disease. Appl Neurophysiol 1987;50: 344-346.

46 Ranson SW, Ranson SW Jr: Efferent fibers of the corpus striatum; in Putnam TJ (ed): The Diseases of the Basal Ganglia. New York, Hafner Publishing, 1966, pp 69-76. 